\title{
A tribute to Syo Kurokawa (1926-2010)
}

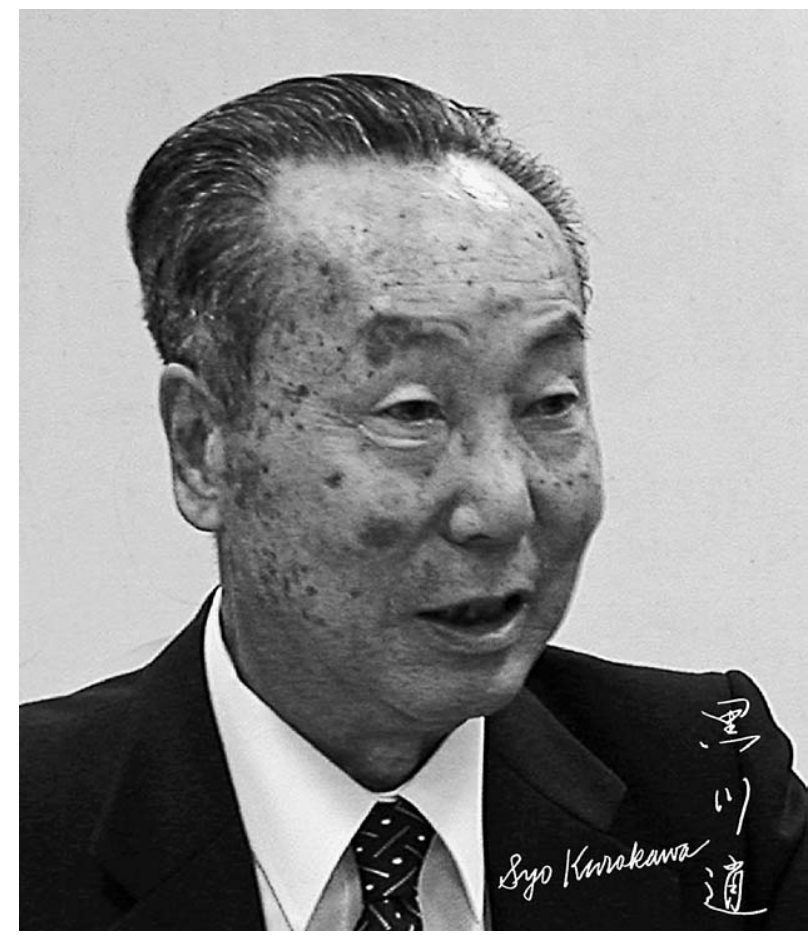

Dr. Syo Kurokawa, Researcher Emeritus of the National Science Museum, passed away on September 16, 2010. He was a renowned scholar and the winner of the Acharius Medal of the International Association of Lichenology in 1994.

Dr. Kurokawa was born on July 15, 1926 and graduated in 1951 from the Tokyo University of Literature \& Science (predecessor to the present University of Tsukuba). He began studying lichens under the guidance of the late Dr. Y. Asahina and received a Doctor of Science from the University with a thesis entitled The species of Anaptychia, with a new sub generic classification. Later, the thesis was published as 'A monograph of the genus Anaptychia' (Beihefte. Nova Hedwigia 6, 1962), which was one of the most outstanding papers on the genus Anaptychia (s. lat).
As is well known, Syo Kurokawa published numerous papers on the genus Parmelia (s. lat.). Among them, 'Studies on Parmelia subgenus Parmelia' by Hale M. E. and Kurokawa, S. (Contributions to the United States National Herbarium 36: 121-191. 1964) should be mentioned especially. Hale and Kurakawa evaluated the importance of rhizine characteristics as well as those found on a thallus in Parmelia (s. lat.) and used them to delimit both species and generic characters. The infrageneric taxa recognized by them are mostly treated as independent genera based on molecular data. Kurokawa also conducted researches on many other genera in Japan of which Anzia, Cetraria, Parmelia (s. str.), Peltigera, Pilophorus and Xanthoparmelia merit particular mention. He brought the Herbarium of the National 
Science Museum, Tokyo (TNS), up to a world class standard. He also published an exsciccata, 'Lichenes rariores et critici exsiccati, Fasc. I-XIV (a total of 700 individuals, 1966-1996) from TNS and distributed it to leading world herbaria on an exchange basis. He published papers on the use of Parmotrema tinctorum as an indicator of air pollution in urban areas of Japan. Dr. Kurokawa was the most reputable and outstanding lichenologist in Japan and, moreover, in Asia.
His passing is a great loss to not only Japan, but to the lichenological societies in the world. Dr. Kurokawa was respected and loved by many due to his warmth and kindness as well as his active pursuit of academic research. With deepest regret we express our gratitude to Dr. Kurokawa and profound sadness on his parting.

\section{Hiroyuki Kashiwadani}

